\title{
Resposta à mosca-branca (Bemisia tabaci) e ao Tomato severe rugose virus de acessos de Solanum subgênero Leptostemonum
}

\author{
Miguel Michereff-Filho${ }^{1}$; Wesley DB Machini ${ }^{1}$; José L Mendonça ${ }^{1}$; Maria Esther de N Fonseca ${ }^{1}$; Niday \\ AN Fernandes-Acioli²; Leonardo S Boiteux ${ }^{1}$ \\ ${ }^{1}$ Embrapa Hortaliças, C. Postal 218, 70351-970 Brasília-DF; boiteux@cnph.embrapa.br; ${ }^{2}$ UnB, Depto Fitopatologia, 70910-970 Brasília-DF
}

\begin{abstract}
RESUMO
A mosca-branca (Bemisia tabaci) e a infecção por espécies de Begomovirus são dois graves problemas fitossanitários que afetam a produção e qualidade do tomateiro (Solanum lycopersicum) e de outras solanáceas de importância econômica. O presente trabalho foi conduzido sob condições controladas, em casa de vegetação, visando avaliar a resposta ao Tomato severe rugose virus (ToSRV) e à mosca-branca (B. tabaci biótipo B) de 36 acessos de espécies relacionadas ao gênero Solanum subgênero Leptostemonum (= grupo das solanáceas providas de espinhos). A inoculação de ToSRV foi realizada em mudas (43 dias após o semeio) utilizando-se um colônia virulífera de B. tabaci biótipo B. Duas cultivares de tomateiro foram incluídas como testemunhas suscetíveis. A avaliação ao ToSRV foi feita de acordo com uma escala de severidade de sintomas e a presença de infecção sistêmica foi verificada via reação em cadeia da polimerase (PCR) com 'primers' universais para espécies de Begomovirus. A maioria dos acessos apresentou uma resposta do tipo resistência ou quase imunidade ao ToSRV, não apresentando sintomas evidentes e nenhum indício de infecção sistêmica ou acumulação viral. Um grupo reduzido de acessos de $S$. stramonifolium, $S$. asperolanatum e $S$. jamaiscense apresentou uma resposta do tipo tolerância, caracterizada por baixa acumulação viral e sintomas suaves. O acesso $S$. mammosum 'CNPH 035', embora tolerante, foi o único que apresentou sintomas mais evidentes de infecção viral e acumulação de ToSRV. O mesmo grupo de 36 acessos foi avaliado em relação à colonização por $B$. tabaci em testes de livre escolha. Diferenças significativas foram observadas entre acessos para oviposição e o número de ninfas no quarto instar, indicando a presença de fatores de resistência ao inseto. Dez acessos de $S$. asperolanatum, $S$. stramonifolium, $S$. paniculatum e $S$. syssimbriifolium se mostraram completamente livres de oviposição. Desta forma, esses acessos do subgênero Leptostemonum podem ser considerados potenciais fontes de genes de resistência tanto para $B$. tabaci quanto para ToSRV. Essa diversidade genética pode ser transferida para outras espécies do gênero Solanum via técnicas de biologia celular e/ou isolamento e mobilização desses genes via transgenia. Os resultados também sugerem que, em condições naturais, espécies do subgênero Leptostemonum não representam importantes fontes de inóculo de ToSRV e/ou hospedeiras alternativas para B. tabaci.
\end{abstract}

Palavras-chave: Solanáceas espinhosas, Begomovirus, aleirodídeo, resistência, jurubebas.

\begin{abstract}
Reaction to whitefly (Bemisia tabaci) and Tomato severe rugose virus of Solanum subgenus Leptostemonum accessions
\end{abstract}

The whitefly (Bemisia tabaci) and the infection by Begomovirus species are two major problems affecting yield and quality of the tomato (Solanum lycopersicum) crop as well as other Solanaceae species of economic importance. The present work was conducted aiming to characterize the reaction of 36 accessions of the genus Solanum subgenus Leptostemonum (= spiny Solanum species) and closely related species to Tomato severe rugose virus (ToSRV) and B. tabaci. Seedlings of the accessions (43 days after sowing) were exposed under greenhouse conditions to viruliferous whiteflies $(B$. tabaci biotype B) carrying an isolate of ToSRV. Two susceptible tomato cultivars were used as susceptible controls. Reaction to the virus was evaluated using a symptom severity scale and the systemic ToSRV infection was evaluated via PCR with universal begomovirus primers. A group of accessions from S. stramonifolium, $S$. asperolanatum, and $S$. jamaiscense displayed mild symptoms and low virus accumulation. The accession $S$. mammosum ' $\mathrm{CNPH}$ 035', even though tolerant, was the only one displaying clear ToSRV symptoms and conspicuous systemic spread of the virus. The remaining accessions were found to be free of ToSRV symptoms and with no indication of systemic infection. This germplasm collection was also evaluated to B. tabaci in a free-choice assay under greenhouse conditions. Significant differences were observed for the number of eggs and number of $4^{\text {th }}$ instar nymphs. A group of ten accessions from $S$. asperolanatum, $S$. stramonifolium, $S$. paniculatum, and $S$. syssimbrifolium displayed no signs of whitefly infestation. Therefore, accessions of the subgenus Leptostemonum might represent potential sources of resistance genes to both $B$. tabaci and ToSRV. This genetic diversity might be transferred to other Solanum species via conventional and/or transgenic approaches. Our results also indicated that these spiny Solanum species might have minor importance either as reservoirs of begomovirus or as alternative hosts of $B$. tabaci under natural conditions.

Keywords: spiny solanaceous, Begomovirus, whiteflies, resistance, jurubebas.

(Recebido para publicação em 20 de julho de 2011; aceito em 11 de julho de 2012) (Received on July 20, 2011; accepted on July 11, 2012)

$\mathrm{O}_{\mathrm{d}=0}^{\mathrm{s}}$ gênero Solanum é o mais numeroso dentro da família Solanaceae, sendo composto por mais de 1.400 espécies, incluindo plantas de importância econômica tais como o tomateiro (Solanum lycopersicum), batata $(S$. tuberosum), berinjela ( $S$. melongena) e jiloeiro (S. gilo) (Hawkes, 1999).
O gênero Solanum possui uma ampla distribuição geográfica, sendo a América do Sul um dos centros de diversidade genética de muitos grupos genéricos 
e infra-genéricos (Hawkes, 1999; Agra, 2007). Um grupo importante, que compreende cerca de 450 espécies endêmicas do Brasil e dos Neotrópicos, está classificado dentro do gênero Solanum subgênero Leptostemonum, também referido como o "grupo das solanáceas espinhosas" (Levin et al., 2006; Chiarini \& Barboza, 2007; Agra et al., 2009).

Muitas das espécies do subgênero Leptostemonum são dotadas de variáveis densidades e topologia de espinhos sendo conhecidas, de maneira geral, como "jurubebas" (Agra et al., 2009). Solanum asperolanatum, S. stramonifolium, S. paniculatum, S. subinerme, S. jamaiscense, $S$. sisymbriifolium e $S$. mammosum são algumas das espécies alocadas neste subgênero (Levin et al., 2006; Weese \& Bohs, 2007; Agra et al., 2009). Solanum paniculatum ("jurubeba verdadeira") e S. asperolanatum são plantas arbustivas com ampla dispersão geográfica desde a Patagônia até regiões da América Tropical (Levin et al., 2006; Weese \& Bohs, 2007). Solanum stramonifolium, $S$. subinerme e $S$. jamaiscense (mais adaptada a ambientes úmidos) são arbustos com distribuição na região norte da América do Sul, incluindo Brasil, Colômbia, Venezuela, Peru e Guianas (Agra et al., 2009). Solanum sisymbriifolium ("joá-vermelho”) é uma planta nativa da América do Sul, de porte ereto, anual ou perene, rizomatosa e com frutos de coloração vermelha. Solanum mammosum é uma planta arbustiva que apresenta frutos amarelos (quando maduros) e de formato peculiar, caracterizado pela presença de protuberâncias bem marcantes (Levin et al., 2006; Agra et al., 2009).

O aleirodídeo (mosca-branca) Bemisia tabaci Genn. (Ordem: Hemiptera, Subordem: Sternorrhyncha e família: Aleyrodidae) é uma das principais pragas de muitas solanáceas de importância econômica, reproduzindo-se em mais de 300 hospedeiras alternativas (Byrne \& Bellows, 1991). As moscasbrancas podem causar injúrias indiretas (sucção da seiva e liberação de toxinas) e indiretas, atuando como vetores de espécies do gênero Begomovirus (família Geminiviridae) (Baldin et al., 2005). Os begomovírus são agentes etiológicos das "geminiviroses", importantes doenças do tomateiro e de outras solanáceas nas regiões tropicais e subtropicais (Polston \& Anderson, 1997). Os sintomas típicos de infecção viral incluem nanismo, mosaico amarelo, clorose generalizada, mosqueado, rugosidade e enrolamento das folhas (Giordano et al., 2005a). Até o inicio da década de 1990 os begomovírus eram de ocorrência esporádica e sem importância econômica (Boiteux et al., 2008; Melo et al., 2009). Após a década de 1990, um complexo extremamente diverso de espécies de Begomovirus emergiu no Brasil (Fernandes et al., 2008), coincidindo com a introdução e dispersão do biótipo B do vetor $B$. tabaci no país (Lourenção \& Nagai, 1994). Análises dos genomas virais revelaram um elevado grau de relacionamento genético entre as espécies de Begomovirus reportadas em tomateiro e em plantas daninhas e/ou nativas frequentemente associadas com o cultivo desta hortaliça. Esses dados indicam uma provável transferência natural de segmentos virais entre as espécies que infectam esses diferentes grupos de plantas hospedeiras (Ambrozevícius et al., 2002).

Devido ao avanço dos surtos epidêmicos no Brasil, especialmente em cultivos de tomateiro, torna-se de extrema importância conhecer novas espécies de plantas hospedeiras alternativas de begomovírus e populações de $B$. tabaci presentes nas áreas produtoras. De fato, um número reduzido de estudos encontra-se disponível sobre o comportamento de acessos de espécies pertencentes ao subgênero Leptostemonum frente ao complexo begomovírus/mosca-branca. É também de extremo interesse para o melhoramento genético a identificação de espécies e/ou acessos do gênero Solanum que apresentem resistência aos begomovírus e/ou ao inseto vetor B. tabaci. Neste contexto, o objetivo do presente trabalho foi caracterizar as respostas de diferentes acessos de espécies desse subgênero à infecção por begomovírus e ao inseto vetor $B$. tabaci.

\section{MATERIAL E MÉTODOS}

Material vegetal - Foram utilizados
36 acessos do banco de germoplasma de Solanum subg. Leptostemonum e espécies afins mantidos na Embrapa Hortaliças (Tabela 1). As sementes dos acessos foram semeadas em bandejas de poliestireno expandido (isopor) de 72 células contendo substrato esterilizado.

Ensaio para resposta à infecção por ToSRV - Os experimentos foram realizados em casas de vegetação na Embrapa Hortaliças. As sementes dos acessos das espécies selvagens germinaram de maneira errática. Desta forma, o número de plantas avaliadas foi variável entre os acessos. Para a avaliação da resposta à infecção por uma espécie de Begomovirus, as bandejas contendo plantas com 43 dias após a emergência (DAE) foram acondicionadas em uma casa de vegetação infestada com moscas-brancas (B. tabaci biótipo B) carregando um isolado Tomato severe rugose virus (ToSRV). O inóculo foi mantido em plantas de $S$. lycopersicum 'Tospodoro' (Giordano et al., 2010). Como controles foram utilizados, nos ensaios, plantas sadias de $S$. lycopersicum cultivares 'Viradoro' (Giordano et al., 2000) e 'Tospodoro', ambas suscetíveis a begomovírus. A linhagem 'TX 468-RG', resistente a begomovírus (Giordano et al., 2005b; García-Cano et al., 2008) foi utilizada como testemunha resistente ao ToSRV. Foram conduzidas avaliações semanais via observação visual da expressão de sintomas e a incidência de plantas com sintomas típicos de infecção por ToSRV aos 92, 99 e 106 DAE. A resposta à infecção foi estimada visualmente utilizando-se a seguinte escala de notas: $1=$ ausência de sintomas, $2=$ amarelecimento e mosaico suave, $3=$ mosaico, enrugamento, clorose internerval e epinastia e 4= mosaico, enrugamento severo e nanismo (Giordano et al., 2005b).

Purificação e estimativa da concentração do DNA total de tecidos infectados - A purificação de DNA total dos tecidos foi feita usando o método CTAB, seguindo o protocolo padrão com algumas adaptações (Boiteux et al., 1999). A concentração do DNA foi ajustada para $20 \mathrm{ng} / \mu \mathrm{L}$ em TE (Tris 0,01M; EDTA 0,001M; pH 7,0).

Avaliação de plantas com infecção sistêmica por Begomovirus via PCR - 
Segmentos dos DNA-A e DNA-B viral foram amplificados via PCR, sendo essa realizada em termo-cicladores do tipo PCR System 9700 (Applied Biosystems). Os componentes, volumes e concentrações foram: $3,0 \mu \mathrm{L}$ de DNA genômico (3 ng/ $\mu \mathrm{L}) ; 1,3 \mu \mathrm{L}$ de tampão 10X (100 $\mathrm{mM}$ Tris-HCl, $500 \mathrm{mM} \mathrm{KCl}, \mathrm{pH} 8.3$ ) para Taq DNA Polimerase; 1,04 $\mu \mathrm{L}$ de dNTPs 2,5 mM; 1,5 $\mu \mathrm{L}$ de iniciadores ('primers') a $10 \mathrm{ng} / \mu \mathrm{L}$ e $0,2 \mu \mathrm{L}$ de enzima Taq DNA Polimerase. O volume final foi completado para $13 \mu \mathrm{L}$ com $4,92 \mu \mathrm{L}$ de água deionizada (processo milli- $\left.Q^{\circledR}\right)$ e autoclavada. Os pares de 'primers' universais utilizados foram 'BegoAFor1'/'BegoARev1' para um segmento do DNA-A (Ha et al., 2006) e 'PBL1v2040'/'PCRc1' para um segmento do DNA-B (Rojas et al., 1993). O perfil de amplificação consistiu de 35 ciclos de desnaturação a $94^{\circ} \mathrm{C}$ por 4 minutos, anelamento dos 'primers' a $50^{\circ} \mathrm{C}$ por 1 minuto e extensão a $72^{\circ} \mathrm{C}$ por 3 minutos, terminando em 7 minutos a $72^{\circ} \mathrm{C}$. Os amplicons foram analisados em géis de agarose $1 \%(\mathrm{p} / \mathrm{v})$, corados com brometo de etídeo e visualizados sob luz ultravioleta.

Sequenciamento de segmentos genômicos dos DNA-A e DNA-B em tecidos dos acessos de Solanum subg. Leptostemonum - Os amplicons foram separados em eletroforese e diretamente sequenciados utilizando o protocolo BigDye $^{\text {TM }}$ Terminator Cycle Sequencing Ready Reaction Kit version 3.1 (Applied Biosystems). A identidade do isolado de ToSRV foi feita via sequenciamento, realizado em um sequenciador $A B I$ PRIM 3100 da Embrapa Hortaliças, utilizando o kit ABI Prism BigDye version 3.0 chemistry (Applied Biosystems).

Ensaio de preferência de oviposição da mosca-branca - Foi realizado um teste com chance de escolha em condições de casa de vegetação. Mudas de pepino (Cucumis sativus) cv. Caipira, transplantadas para vasos de $2 \mathrm{~L}$ de substrato, mantidas em uma casa de vegetação isolada, foram utilizadas para multiplicação da população de mosca-branca. As sementes dos acessos de Solanum subg. Leptostemonum foram semeadas em bandejas de isopor de 72 células. Plantas com 99 DAE foram acondicionadas em telado e colocadas em gaiola de tubo PVC de 0,50 m cobertas com tecido 'voil', visando manter os acessos temporariamente livres da presença de insetos vetores. Dentro das gaiolas foi instalada uma armadilha amarela adesiva para captura das moscas-brancas. Com 141 DAE as mudas (de cada acesso de Solanum) foram transplantadas para vasos de 3 L e dispostas aleatoriamente em seis gaiolas. Cada gaiola correspondeu a um bloco e recebeu uma planta de cada acesso. Aos 142 DAE as plantas de pepino previamente utilizadas para criação de moscas-brancas foram levadas para as gaiolas onde estavam as mudas dos acessos de Solanum. Cada planta de pepino continha aproximadamente 100 adultos de $B$. tabaci e antes da sua introdução na gaiola retirou-se a armadilha adesiva. Duas plantas de pepino infestadas com mosca-branca foram deixadas em cada gaiola durante 48 horas. A avaliação dos níveis de oviposição da mosca-branca nos acessos de Solanum foi avaliada aos 148 DAE, mediante coleta de cinco folhas/planta, totalizando-se 30 folhas por acesso. As amostras foliares foram ensacadas, etiquetadas e conservadas em freezer, para posterior contagem do número de ovos. O número de ninfas de quarto instar (pupas) foi avaliado aos 160 DAE com o auxílio de um microscópio estereoscópico binocular, com aumento de 40X. O delineamento experimental foi em blocos casualizados, totalizando seis repetições por acesso, com uma planta por repetição. Os dados foram transformados em log $(\mathrm{x}+1)$, submetidos à análise de variância e as médias foram comparadas pelo teste de Scott-Knott ao nível de 5\% de probabilidade, utilizando-se o programa estatístico SAEG.

Biotipagem molecular da população de mosca-branca usada nos testes de transmissão viral e resistência - Foram coletados 10 indivíduos adultos por acesso, os quais foram macerados individualmente em tubos de microcentrífuga. Amostras do DNA das moscas-brancas foram purificadas separadamente usando o método de CTAB. O gene mitocondrial da citocromo oxidase subunidade I (mt COI) foi amplificado via PCR usando "primers" específicos (Simon et al.,
1994; Frohlich et al., 1999; Brown, 2000; de Barro et al., 2000; Boykin et al., 2007). Uma alíquota do produto de PCR foi utilizada para o sequenciamento direto utilizando-se o Kit BigDye ${ }^{\circledR}$ versão 3 em um sequenciador ABI 3100 do Laboratório de Análise Genômica da Embrapa Hortaliças.

\section{RESULTADOS E DISCUSSÃO}

As cultivares de tomateiro 'Viradoro' e 'Tospodoro' mostraram severos sintomas, indicando que o sistema de inoculação foi eficiente. A linhagem 'TX 468-RG' apresentou resposta resistente ao ToSRV, confirmando dados anteriores com este e outros begomovírus (Garcia-Cano et al., 2008; Pereira-Carvalho et al., 2010). A maioria dos acessos de Solanum subg. Leptostemonum apresentou uma resposta do tipo resistência ou quase imunidade ao ToSRV, não apresentando sintomas evidentes e nenhum indício de infecção sistêmica ou acumulação viral (até aos 60 dias pós-inoculação). Um grupo reduzido de acessos de $S$. stramonifolium, S. asperolanatum e $S$. jamaiscense apresentou uma resposta do tipo tolerância, caracterizada por baixa acumulação viral e sintomas suaves. O acesso $S$. mammosum ' $\mathrm{CNPH}$ 035', embora tolerante, foi o único a apresentar sintomas mais nítidos bem como acumulação de ToSRV.

De acordo com os dados de sequenciamento, a população de $B$. tabaci utilizada nos dois ensaios para avaliação dos acessos de Solanum subg. Leptostemonum apresentaram maior relacionamento genético com o biótipo B (dados não apresentados). Foram observadas diferenças significativas entre acessos considerando-se o número de ovos e de ninfas de quarto instar da mosca-branca nas folhas. Os acessos com menor número de ovos (= menor preferência para oviposição) foram: 'CNPH 001', 'CNPH 002', 'CNPH 004', 'CNPH 019', 'CNPH 023', 'CNPH 027', 'CNPH 029', 'CNPH 034', 'CNPH 045' e 'CNPH 046'. Os acessos 'CNPH 003', 'CNPH 011', 'CNPH 018', 'CNPH 047' e 'CNPH 048' apresentaram uma resposta intermediária. Os demais acessos apresen- 
Tabela 1. Reação a Bemisia tabaci biótipo B de acessos de Solanum subgênero Leptostemonum e espécies afins em teste com chance de escolha (reaction to Bemisia tabaci biotype B of accessions belonging to Solanum subgenus Leptostemonum in free-choice test). Brasília, Embrapa Hortaliças, 2010.

\begin{tabular}{|c|c|c|c|}
\hline \multirow[t]{2}{*}{$\begin{array}{l}\text { Código do } \\
\text { acesso }\end{array}$} & \multirow[t]{2}{*}{$\begin{array}{l}\text { Espécie de } \\
\text { Solanum }\end{array}$} & \multicolumn{2}{|c|}{$\begin{array}{l}\text { Ocorrência/amostra de cinco } \\
\text { folhas por acesso (média } \pm \text { erro } \\
\text { padrão da média) }\end{array}$} \\
\hline & & Ovos & Ninfas de $4^{\circ}$ ínstar \\
\hline 'CNPH 001' & S. asperolanatum & $0,00 \pm 0,00 \mathrm{c}^{1}$ & $0,00 \pm 0,0 \mathrm{c}$ \\
\hline 'CNPH 002' & S. asperolanatum & $0,00 \pm 0,00 \mathrm{c}$ & $0,00 \pm 0,0 \mathrm{c}$ \\
\hline 'CNPH 003' & S. asperolanatum & $4,67 \pm 2,03 b$ & $1,50 \pm 0,5 \mathrm{c}$ \\
\hline 'CNPH 004' & S. asperolanatum & $0,00 \pm 0,00 \mathrm{c}$ & $0,00 \pm 0,0 \mathrm{c}$ \\
\hline 'CNPH 005' & S. asperolanatum & $16,00 \pm 2,83 \mathrm{a}$ & $1,75 \pm 0,63 \mathrm{c}$ \\
\hline 'CNPH 006' & S. asperolanatum & $27,25 \pm 4,87 \mathrm{a}$ & $13,00 \pm 2,38 b$ \\
\hline 'CNPH 007' & S. asperolanatum & $1,60 \pm 1,03 \mathrm{bc}$ & $1,20 \pm 0,80 \mathrm{c}$ \\
\hline 'CNPH 008' & S. asperolanatum & $21,40 \pm 2,47 \mathrm{a}$ & $8,20 \pm 0,89 b$ \\
\hline 'CNPH 010' & S. asperolanatum & $32,67 \pm 2,57 \mathrm{a}$ & $21,00 \pm 7,62 \mathrm{a}$ \\
\hline 'CNPH 011' & S. asperolanatum & $4,20 \pm 2,46 b$ & $2,00 \pm 2,00 \mathrm{c}$ \\
\hline 'CNPH 012' & S. asperolanatum & $3,00 \pm 3,00 \mathrm{bc}$ & $0,50 \pm 0,50 \mathrm{c}$ \\
\hline 'CNPH 013' & S. asperolanatum & $17,67 \pm 1,25 \mathrm{a}$ & $7,33 \pm 5,23 \mathrm{c}$ \\
\hline 'CNPH 015 ' & S. asperolanatum & $17,00 \pm 2,10 \mathrm{a}$ & $6,00 \pm 0,26 b$ \\
\hline 'CNPH 016' & S. asperolanatum & $18,33 \pm 1,77 \mathrm{a}$ & $4,33 \pm 1,87 \mathrm{c}$ \\
\hline 'CNPH 017 ' & S. asperolanatum & $19,83 \pm 2,09 \mathrm{a}$ & $6,17 \pm 0,46 b$ \\
\hline 'CNPH 018 ' & S. asperolanatum & $5,75 \pm 3,09 b$ & $3,00 \pm 2,78 \mathrm{c}$ \\
\hline 'CNPH 019' & S. stramonifolium & $0,75 \pm 0,75 \mathrm{c}$ & $0,75 \pm 0,75 \mathrm{c}$ \\
\hline 'CNPH 020’ & S. stramonifolium & $16,33 \pm 2,18 \mathrm{a}$ & $0,67 \pm 0,67 \mathrm{c}$ \\
\hline 'CNPH 021' & S. stramonifolium & $53,00 \pm 17,46 a$ & $34,50 \pm 9,36 \mathrm{a}$ \\
\hline 'CNPH 023' & S. stramonifolium & $0,00 \pm 0,00 \mathrm{c}$ & $0,00 \pm 0,00 \mathrm{c}$ \\
\hline 'CNPH 024' & S. stramonifolium & $18,00 \pm 3,80 \mathrm{a}$ & $16,00 \pm 3,60 \mathrm{a}$ \\
\hline 'CNPH 025' & S. stramonifolium & $16,00 \pm 2,03 \mathrm{a}$ & $1,00 \pm 1,00 \mathrm{c}$ \\
\hline 'CNPH 027' & S. paniculatum & $0,00 \pm 0,00 \mathrm{c}$ & $0,00 \pm 0,00 \mathrm{c}$ \\
\hline 'CNPH 028' & S. paniculatum & $1,00 \pm 0,70 \mathrm{bc}$ & $1,00 \pm 1,00 \mathrm{c}$ \\
\hline 'CNPH 029' & S. paniculatum & $0,00 \pm 0,00 \mathrm{c}$ & $0,00 \pm 0,00 \mathrm{c}$ \\
\hline 'CNPH 030' & S. paniculatum & $2,00 \pm 1,81 \mathrm{bc}$ & $0,00 \pm 0,00 \mathrm{c}$ \\
\hline 'CNPH 031' & S. subinerme & $11,67 \pm 2,69 \mathrm{a}$ & $7,33 \pm 0,84 \mathrm{~b}$ \\
\hline 'CNPH 033' & S. jamaiscense & $13,67 \pm 1,85 \mathrm{a}$ & $4,50 \pm 0,19 b$ \\
\hline 'CNPH 034' & S. sisymbriifolium & $0,00 \pm 0,00 \mathrm{c}$ & $0,00 \pm 0,00 \mathrm{c}$ \\
\hline 'CNPH 035' & S. mamosum & $0,00 \pm 0,00 \mathrm{c}$ & $0,00 \pm 0,00 \mathrm{c}$ \\
\hline 'CNPH 045' & Solanum sp. & $0,00 \pm 0,00 \mathrm{c}$ & $0,00 \pm 0,00 \mathrm{c}$ \\
\hline 'CNPH 046' & Solanum sp. & $0,00 \pm 0,00 \mathrm{c}$ & $0,00 \pm 0,00 \mathrm{c}$ \\
\hline 'CNPH 047' & Solanum sp. & $2,80 \pm 1,02 \mathrm{~b}$ & $1,80 \pm 0,80 \mathrm{c}$ \\
\hline 'CNPH 048' & Solanum sp. & $8,67 \pm 1,56 b$ & $2,00 \pm 1,37 \mathrm{c}$ \\
\hline
\end{tabular}

${ }^{1}$ Médias seguidas pela mesma letra na coluna não diferem entre si de acordo com o teste de Scott-Knott ( $5 \%$ de significância) ( ${ }^{1}$ means followed by the same letter in column do not differ by the Scott-Knott test $(\mathrm{p}=0.05))$.

taram níveis maiores de oviposição de B. tabaci (Tabela 1). Os resultados sugerem a existência de não-preferência para oviposição em alguns acessos do gênero Solanum subg. Leptostemonum e de espécies afins. Os acessos que apresentaram as maiores densidades populacionais de ninfas de quarto instar foram o 'CNPH 021', 'CNPH 024' e 'CNPH 010', respectivamente (Tabela 1). Os acessos com melhor desempenho foram: 'CNPH 001', 'CNPH 002', 'CNPH 004' (S. asperolanatum); 'CNPH 023' ( $S$. stramonifolium); 'CNPH 027', 'CNPH 029' (S. paniculatum); 'CNPH 034' ( $S$. sisymbriifolium); 'CNPH 045' e 'CNPH 046' (espécies ainda não-classificadas de Solanum). Assim, não surpreende o fato de que estes acessos também se mostraram resistentes ao ToSRV (que pode, desta forma, estar associada com a interferência na transmissão do vírus pela mosca-branca). No entanto, é interessante notar que embora o acesso $S$. mammosum 'CNPH 035' tenha sido o único a apresentar sintomas um pouco mais evidentes de infecção e acumulação de ToSRV, este também não foi eficientemente colonizado pelo vetor.

Os níveis elevados de resistência ao ToSRV observados em diferentes acessos de Solanum podem se manifestar em um ou em dois níveis: a entrada do patógeno (referente à eficiência de transmissão do vírus pelo vetor, o que implica o envolvimento de fatores de resistência ao vetor) e/ou a infecção local e/ou sistêmica. A reação dos acessos ao ToSRV foi avaliada com uma escala de notas de severidade de sintomas. A ocorrência de infecção sistêmica foi verificada via reação em cadeia da polimerase (PCR) com 'primers' universais para espécies de Begomovirus. Desta forma, as metodologias de avaliação da resposta a ToSRV empregadas não podem discriminar esses dois tipos de resistência. Uma maneira de comprovar que um determinado acesso apresenta resistência simultânea ao ToSRV e à B. tabaci será a condução de ensaios adicionais de inoculação via enxertia (com material infectado) ou via bombardeamento (biolística) com DNA viral.

O presente estudo enfatizou metodologicamente, a detecção de fatores de resistência relacionados ao comportamento de seleção da planta hospedeira pela mosca-branca. No entanto, não podem ser descartados efeitos negativos de alguma característica dos diferentes acessos de Solanum subg. Leptostemonum na biologia do inseto (sobrevivência de ninfas do $1^{\circ}$ ao $4^{\circ}$ ínstar), ou seja, a existência de antibiose. 
Isto será devidamente avaliado em estudos futuros. Nesse sentido, é interessante mencionar que Mairesse (2005) observou que o extrato aquoso de folhas de $S$. paniculatum (uma das espécies com acessos avaliados no presente estudo) propiciou efeitos deletérios em lagartas de segundo instar de Spodoptera frugiperda, quando adicionado à dieta artificial do inseto. Também há relato da ação inseticida do extrato etanólico de frutos de $S$. stramonifolium sobre larvas de terceiro instar do mosquito Anopheles darlingi, principal vetor de malária na região amazônica (Rodrigues et al., 2004).

Muitas espécies do gênero Solanum subg. Leptostemonum são endêmicas no Brasil (Agra, 2007) e apresentam ciclo de vida perene ou semi-perene, podendo, desta forma, manter populações virais e/ou de B. tabaci entre as estações de cultivo. Neste aspecto, elas representariam um importante componente epidemiológico, contribuindo para a emergência e/ou a manutenção de espécies virais bem como servir como sítios de geração de novos recombinantes, como tem sido observado em condições naturais no Brasil (Ambrozevícius et al., 2002). Existem registros prévios indicando $S$. paniculatum como uma suposta hospedeira de B. tabaci (Arioli \& Link, 1986), provavelmente do biótipo A. No entanto, o presente estudo sugere que, em condições naturais, os acessos de várias espécies de 'jurubebas' não representam importantes fontes de inóculo de begomovírus e/ou hospedeiras alternativas para B. tabaci biótipo B.

Em conclusão, os resultados obtidos mostram uma grande diversidade de fontes de resistência a ToSRV em acessos do gênero Solanum subg. Leptostemonum e espécies afins. Devido os níveis de resistência apresentados, muitos destes acessos podem ser considerados promissores para utilização em programas de melhoramento genético. No nosso estudo merecem destaque especial dez acessos distribuídos nas espécies S. stramonifolium, S. asperolanatum, S. sisymbrifolium e $S$. paniculatum que combinaram resistência do tipo imunidade ao ToSRV e não infestação por B. tabaci (ausência de oviposição).
A infecção por espécies de Begomovirus e as injúrias causadas por seu vetor (biótipos de B. tabaci) constituem atualmente um dos mais sérios problemas na cultura do tomateiro no Brasil (Boiteux et al., 2007; Fernandes et al., 2008). Para contornar estes problemas, programas de melhoramento genético têm buscado desenvolver cultivares de $S$. lycopersicum resistentes a partir de fontes de amplo espectro de resistência, incluindo germoplasma de outras espécies do gênero Solanum para posterior introgressão (Giordano et al., 2005b).

No aspecto fitotécnico, a ausência de ataque da mosca-branca e resistência ao ToSRV em parte dos acessos do gênero Solanum subg. Leptostemonum é mais uma característica de interesse que se soma a outras vantagens previamente identificadas nesse germoplasma (Mendonça et al., 2009a; 2009b), incluindo resistência à murchabacteriana (Ralstonia solanacearum) e a espécies de nematóides-dasgalhas (Meloidogyne javanica e M. mayaguensis). Esses atributos vêm sendo utilizados, atualmente, apenas no desenvolvimento de porta-enxertos multi-resistentes para tomateiro e outras solanáceas. No entanto, essa abundância de características/genes de interesse nesses acessos de Solanum subg. Leptostemonum e espécies afins podem servir como um estímulo para novas ações de pesquisa visando introgredir essa diversidade para outras espécies do gênero Solanum via estratégias de biologia celular e/ou por meio do isolamento e mobilização destes genes via transgenia/cisgenia.

\section{AGRADECIMENTOS}

Wesley Machini (graduando em Agronomia das Faculdades Integradas da Terra de Brasília) foi bolsista PIBIC/ CNPq durante o período de realização do presente trabalho. Maria Esther de N Fonseca e Leonardo S Boiteux são bolsistas de produtividade $\mathrm{CNPq}$ (MCT).

\section{REFERÊNCIAS}

AGRA MF. 2007. Diversity and distribution of Solanum subg. Leptostemonum in Brazil. Acta
Horticulturae 745: 31-43.

AGRA MF; NURIT-SILVA K; BERGER LR. 2009. Flora da Paraíba, Brasil: Solanum L. (Solanaceae). Acta Botanica Brasilia 23: 826-842.

AMBROZEVÍCIUS LP, CALEGARIO RF, FONTES EPB, CARVALHO MG; ZERBINI FM. 2002. Genetic diversity of Begomovirus infecting tomato and associated weeds in Southeastern Brazil. Fitopatologia Brasileira 27: $372-377$

ARIOLI MCS; LINK D. 1986. Nota de ocorrência de Delphastus argentinicus Nunenmacher, 1937 na região de Santa Maria, RS. Revista Centro de Ciências Rurais, Santa Maria, 16: 57-60.

BALDIN ELL; VENDRAMIM JD; LOURENÇÃO AL. 2005. Resistência de genótipos de tomateiro à mosca-branca Bemisia tabaci (Gennadius) biótipo B (Hemiptera: Aleyrodidae). Neotropical Entomology 34: 435-441.

BOITEUX LS; FONSECA MEN; SIMON PW. 1999. Effects of plant tissue and DNA purification method on randomly amplified polymorphic DNA-based genetic fingerprinting analysis in carrot. Journal of the American Society for Horticultural Science 124: 32-38.

BOITEUX LS; OLIVEIRA VR; SILVA CH; MAKISHIMA N; INOUE-NAGATA AK; FONSECA MEN; GIORDANO LB. 2007. Reaction of tomato hybrids carrying the $T y$ - 1 locus to Brazilian bipartite Begomovirus species. Horticultura Brasileira 25: 20-23.

BOITEUX LS; MELO PCT; VILELA NJ. 2008. Tomate para Consumo in natura. p. 557-567. In: ALBUQUERQUE ACS; SILVA AG (eds). Desenvolvimento da Agricultura Tropical: Quatro Décadas de Inovações Tecnológicas, Institucionais e Politicas. Brasília, DF: Embrapa, volume 1.

BOYKIN LM; SHATTERS JRRG; ROSELL RC; MCKENZIE CL; BAGNALL RA; DE BARRO P; FROHLICH DR. 2007. Global relationships of Bemisia tabaci (Hemiptera: Aleyrodidae) revealed using Bayesian analysis of mitochondrial COI DNA sequences. Molecular Phylogenetics and Evolution 44: 1306-1319.

BROWN JK. 2000. Molecular markers for the identification and global tracking of whitefly vector-Begomovirus complexes. Virus Research 71: 233-260.

BYRNE DN; BELLOWS JR TS. 1991. Whitefly biology. Annual Review of Entomology 36: 431-457.

CHIARINI FE; BARBOZA GE. 2007. Placentation patterns and seed number in fruits of South American Solanum subgen. Leptostemonum (Solanaceae) species. Darwiniana 45:163-174.

DE BARRO PJ; DRIVER F; TRUEMAN JWH; CURRAN J. 2000. Phylogenetic relationships of world populations of Bemisia tabaci (Gennadius) using ribosomal ITS1. Molecular Phylogenetics and Evolution 16: 29-36. 
FERNANDES FR; ALBUQUERQUE LC; GIORDANO LB; BOITEUX LS; DE AVILA AC; INOUE-NAGATA AK. 2008. Diversity and prevalence of Brazilian bipartite Begomovirus species associated to tomatoes. Virus Genes 36: 251-258.

FROHLICH DR; TORREZ-JEREZ I; BEDFORD ID; MARKHAM PG; BROWN JK. 1999. A phylogeographic analysis of the Bemisia tabaci species complex based on mitochondrial DNA markers. Molecular Ecology 8: 1683-1691.

GARCÍA-CANO E; RESENDE RO; BOITEUX LS; GIORDANO LB; FERNÁNDEZMUÑOZ R; MORIONES E. 2008. Phenotypic expression, stability, and inheritance of a recessive resistance to monopartite begomoviruses associated with tomato yellow leaf curl disease in tomato. Phytopathology 98: 618-627.

GIORDANO LB; ÁVILAAC; CHARCHAR JM; BOITEUX LS; FERRAZ E. 2000. 'Viradoro': A tospovirus-resistant processing tomato cultivar adapted to tropical environments. HortScience 35: 1368-1370.

GIORDANO LB; FONSECA MEN; SILVA JBC; INOUE-NAGATAAK; BOITEUX LS. 2005a. Efeito da infecção precoce por Begomovirus com genoma bipartido em características de frutos de tomate industrial. Horticultura Brasileira 23:815-818.

GIORDANO LB; SILVA-LOBO VL; SANTANA FM; FONSECA MEN; BOITEUX LS. 2005b. Inheritance of resistance to bipartite Tomato chlorotic mottle begomovirus derived from Lycopersicon esculentum cv 'Tyking'. Euphytica 143: 27-33.

GIORDANO LB; BOITEUX LS; QUEZADODUVAL AM; FONSECA MEN; RESENDE FV; REISA; GONZÁLEZ M; NASCIMENTO
WM; MENDONÇAJL. 2010. BRS Tospodoro: a high lycopene processing tomato cultivar adapted to organic crop systems and with multiple resistance to pathogens. Horticultura Brasileira 28: 241-245.

HA C; COOMBS S; REVILL P; HARDING R; VU M; DALE J. 2006. Corchorus yellow vein virus, a New World geminivirus from the Old World. Journal of General Virology 87: 997-1003.

HAWKES JG. 1999. The economic importance of the family Solanaceae. In: NEE M; SYMON DE; LESTER RN; JESSOP JP (eds). Solanaceae IV Advances in Botany and Utilization. Royal Botanic Gardens, Kew, Surrey, Reino Unido.

LEVIN RA; MYERS NR; BOHS L. 2006. Phylogenetic relationships among the "spiny Solanums" (Solanum subgenus Leptostemonum, Solanaceae). American Journal of Botany 93: 157-169.

LOURENÇÃO AL; NAGAI H. 1994. Surtos populacionais de Bemisia tabaci no Estado de São Paulo. Bragantia 53: 53-59.

MAIRESSE LAS. 2005. Avaliação da bioatividade de extratos de espécies vegetais, enquanto excipientes de aleloquímicos. Santa Maria: UFSM-RS (Tese doutorado).

MELO PCT, MELO AMT, BOITEUX LS. 2009. Overview and perspectives of tomato breeding for fresh market adapted to mild tropical climates of Brazil. Acta Horticulturae 821: 55-62.

MENDONÇA JL; LOPES CA; BOITEUX LS; MOITA AW; OLIVEIRA AR. 2009a. Compatibilidade de enxertia de tomateiro e jurubeba ( $S$. stramonifolium e $S$. asperolanatum). Anais do $3^{\circ}$ Congresso Brasileiro de Tomate Industrial e $1^{\circ}$ Seminário
Nacional de Tomate de Mesa, Goiânia-GO (CD-ROM).

MENDONÇA JL; ROSSATO M; SILVA BB; LOPES CA. 2009b. Resistência de jurubebas (Solanum spp.) a duas biovares de Ralstonia solanacearum. Tropical Plant Pathology 34: S32.

PEREIRA-CARVALHO RC; BOITEUX LS; FONSECA MEN; DÍAZ-PENDÓN JA; MORIONES E; FERNÁNDEZ-MUÑOZ R; CHARCHAR JM; RESENDE RO. 2010. Multiple resistance to Meloidogyne spp. and to bipartite and monopartite Begomovirus spp. in wild Solanum (Lycopersicon) accessions. Plant Disease 94: 179-185.

POLSTON JE; ANDERSON PK. 1997. The emergence of whitefly-transmitted geminiviruses in tomato in the western hemisphere. Plant Disease 81: 1358-1369.

RODRIGUES AF; ESCOBAR AL; SANTOS F; AZEVEDO MS. 2004. Atividade larvicida de frutos do Solanum stramonifolium Jacq. contra Anopheles darlingi e a problemática da malária em área indígena. In: SEMINÁRIO DE INICIAÇÃO CIENTÍFICA FUNDAÇÃO UNIVERSIDADE FEDERAL DE RONDÔNIA (UNIR), 13. Anais... Porto Velho, RO: PROPEX/EDUFRO.

SIMON C; FRATI F; BECKEMBACH A; CRESPI B; LIU H; FLOOK, P. 1994. Evolution, weighting and phylogenetic utility of mitochondrial gene sequences and a compilation of conserved polymerase chain reaction primers. Annals of Entomological Society of America 87: 651-701.

WEESE TL; BOHS L. 2007. A three-gene phylogeny of the genus Solanum (Solanaceae). Systematic Botany 32: 445-463. 